\title{
Intracellular survival of Burkholderia cepacia complex isolates in the presence of macrophage cell activation
}

\author{
Lalit S. Saini, ${ }^{1}$ Sara B. Galsworthy, ${ }^{1}$ Michael A. John ${ }^{1,3}$ \\ and Miguel A. Valvano ${ }^{1,2}$
}

Author for correspondence: Miguel A. Valvano. Tel: +1 519661 3996. Fax: +1 5196613499. e-mail:mvalvano@julian.uwo.ca

1,2 Department of
Microbiology and
Immunology ${ }^{1}$ and
Department of Medicine'2,
University of Western
Ontario, London, Ontario,
N6A 5C1, Canada
3 Department of
Microbiology and
Infection Control, London
Health Sciences Centre,
London, Ontario,
N6A 4G5, Canada

1,2 Department of Microbiology and Department of Medicine ${ }^{2}$ University of Western Ontario, London, Ontario

Department of Microbiology and Health Sciences Centre, N6A 4G5 Canada

\begin{abstract}
Strains of the Burkholderia cepacia complex have emerged as a serious threat to patients with cystic fibrosis due to their ability to infect the lung and cause, in some patients, a necrotizing pneumonia that is often lethal. It has recently been shown that several strains of the $B$. cepacia complex can escape intracellular killing by free-living amoebae following phagocytosis. In this work, the ability of two $B$. cepacia complex strains to resist killing by macrophages was explored. Using fluorescence microscopy, electron microscopy and a modified version of the gentamicin-protection assay, we demonstrate that B. cepacia CEP021 (genomovar VI), and Burkholderia vietnamiensis (previously B. cepacia genomovar V) CEP040 can survive in PU5-1.8 murine macrophages for a period of at least $5 \mathrm{~d}$ without significant bacterial replication. Furthermore, bacterial entry into macrophages stimulated production of tumour necrosis factor and primed them to release toxic oxygen radicals following treatment with phorbol myristoyl acetate. These effects were probably caused by bacterial LPS, as they were blocked by polymyxin B. Infected macrophages primed with interferon gamma produced less nitric oxide than interferon-gamma-primed uninfected cells. We propose that the ability of $B$. cepacia to resist intracellular killing by phagocytic cells may play a role in the pathogenesis of cystic fibrosis lung infection. Our data are consistent with a model where repeated cycles of phagocytosis and cellular activation without bacterial killing may promote a deleterious inflammatory response causing tissue destruction and decay of lung function.
\end{abstract}

Keywords: Burkholderia cepacia, macrophage activation, intracellular survival, cystic fibrosis

\section{INTRODUCTION}

Cystic fibrosis (CF), occurring at a frequency of $1: 2500$ live births, is the most common inherited lethal disease of Caucasian individuals. The product of the CF gene is a chloride channel found in both secretory and absorptive epithelia (di Sant'Agnese \& Davis, 1976). Abnormal chloride transport across epithelial cells leads to pancreatic exocrine insufficiency, male and female infertility, and lung disease (Bye et al., 1994; di Sant'Agnese \& Davis, 1976). The highly viscid mucus in

Abbreviations: CF, cystic fibrosis; DCF, dichlorofluorescein; IFN- $\gamma$, interferon gamma; PMA, phorbol myristoyl acetate; PMB, polymyxin B; TNF, tumour necrosis factor. the airways of CF patients may impair normal mucociliary clearance mechanisms, thus allowing colonization by opportunistic micro-organisms (Gilligan, 1991; Govan \& Deretic, 1996). Proteoglycans showing increased sulfation are components of the mucus in the airways, and may also interact with bacteria or their products to further increase mucus viscosity (Cheng $e t$ al., 1989; Gilligan, 1991). In addition, high sodium chloride concentrations in the airway surface fluid from CF patients have been found to inhibit the activity of bactericidal peptides secreted by epithelial cells (Smith et al., 1996). The combination of all these alterations is thought to contribute to recurrent and chronic respiratory tract infections that are the major cause of morbidity and mortality in CF disease (Bals et al., 1999). 
Lung infection in CF individuals exhibits a characteristic age-related pattern involving colonization and intermittent exacerbations caused by Staphylococcus aureus and Haemophilus influenzae in infancy and early childhood, followed almost invariably in adolescence by Pseudomonas aeruginosa (Gilligan, 1991; Govan \& Deretic, 1996). However, more recently and in parallel with an improved life expectancy of CF patients (FitzSimmons, 1996), the spectrum of microbial pathogens has expanded to also include Burkholderia cepacia, which currently can be isolated from as many as $40 \%$ of CF patients (Govan \& Deretic, 1996). Colonization and infection by $B$. cepacia has become a major concern for these patients due to three salient features. First, although most CF patients harbouring B. cepacia show a chronic non-aggressive infection associated with periods of acute exacerbations, up to $20 \%$ exhibit an accelerated clinical deterioration referred to as the cepacia syndrome. This condition is characterized by a rapid reduction of pulmonary function associated with sepsis and high mortality (Govan \& Deretic, 1996; Isles et al., 1984). Second, there is compelling evidence indicating that B. cepacia can be transmitted from patient to patient (Govan et al., 1996). Third, the innate multi-drug resistance of $B$. cepacia has made effective antimicrobial treatment very problematic. B. cepacia is a soil bacterium, metabolically versatile, and taxonomically complex. Several different species can be distinguished by polyphasic taxonomy and PCR-based genetic analysis among isolates from clinical and environmental sources. Since the members of each group are genotypically distinct but have phenotypic traits shared among groups, they are referred to as genomovars. Up to six genomovars are known to occur in $\mathrm{CF}$ patients; these isolates are referred to as the B. cepacia complex (Vandamme et al., 1997). Of these, genomovar III strains occur in approximately $50 \%$ of CF cases colonized with B. cepacia and they are more commonly, but not exclusively, associated with the cepacia syndrome (Vandamme et al., 1997). Members of the other genomovars occur at lower frequencies.

Recent work in various laboratories suggests that $B$. cepacia isolates may be able to survive intracellularly. Burns et al. (1996) reported that a clinical isolate of $B$. cepacia could enter and replicate in the A549 human epithelial carcinoma cell line. Also, B. cepacia-like micro-organisms are endosymbiotically associated with arbuscular mycorrhizal fungi, residing within cytoplasmic vesicles (Perotto \& Bonfante, 1997). More recently, Marolda et al. (1999) have shown that several members of the B. cepacia complex are able to survive within various types of free-living amoebae of the genus Acanthamoeba. It is well established that several microorganisms surviving within amoebae, such as Legionella pneumophila, Mycobacterium avium, Chlamydia pneumoniae and Listeria monocytogenes, are also able to survive and replicate within macrophages (Brown \& Barker, 1999). Therefore, we investigated whether $B$. cepacia complex strains are capable of surviving intracellularly within macrophages, since this property could contribute to its pathogenicity in CF individuals. In the present study, we demonstrate that two clinical isolates of the B. cepacia complex can survive for an extended period of time, as compared to Escherichia coli, in a murine macrophage cell line. We also show that bacterial survival occurs despite macrophage activation following phagocytosis.

\section{METHODS}

Bacterial strains, cell lines and reagents. Clinical isolates of $B$. cepacia from CF patients were obtained from the Vancouver collection, and assigned to individual genomovars by $\mathrm{P}$. Vandamme (Laboratory of Microbiology, University of Gent, Belgium) and E. Mahenthiralingam (Department of Pediatrics, University of British Columbia, Canada). B. cepacia strain CEP021 belongs to the newly defined genomovar VI (P. Vandamme, personal communication). This strain is a nonepidemic isolate obtained from a CF patient in Philadelphia in 1986 that had a different ribotyping profile than the Philadelphia epidemic strain (J. J. Lipuma, personal communication). B. vietnamiensis (formerly B. cepacia complex genomovar V) strain CEP040, originally described as $B$. cepacia PC315 (J. Burns, personal communication) was recovered at the time of autopsy from sputum of a CF patient with necrotizing pneumonia, and is the same isolate used by Burns et al. (1996) to demonstrate invasion and survival in an epithelial cell line. Cultures were grown at $37^{\circ} \mathrm{C}$ in Luria-Bertani (LB) medium. B. cepacia isolates were examined for antibiotic susceptibility to determine their suitability for the intracellular invasion assay (see below). Isolates were grown on plates containing $100 \mu \mathrm{g}$ gentamicin $\mathrm{ml}^{-1}, 100 \mu \mathrm{g}$ kanamycin $\mathrm{ml}^{-1}, 100 \mu \mathrm{g}$ ceftazidime $\mathrm{ml}^{-1}$ (Eli Lilly), $100 \mu \mathrm{g}$ streptomycin $\mathrm{ml}^{-1}$ or $100 \mu \mathrm{g}$ tetracycline $\mathrm{ml}^{-1}$. The strains of

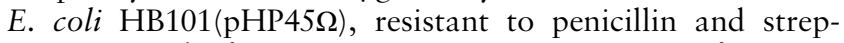
tomycin, and of Listeria monocytogenes 42 were from our laboratory and the E. G. D. Murray culture collection (Dept Microbiology and Immunology, University of Western Ontaro, Canada), respectively. Murine macrophage cell lines PU5-1.8 (ATCC TIB-61) and J774A.1 (ATCC TIB-67), and L929 fibroblasts (ATCC CCL-1) were maintained in RPMI 1640 medium (Life Technologies) supplemented with $10 \%$ $(\mathrm{v} / \mathrm{v})$ fetal bovine serum (Life Technologies), $50 \mathrm{U}$ penicillin $\mathrm{ml}^{-1}$ and $50 \mathrm{U}$ streptomycin $\mathrm{ml}^{-1}$. All chemicals and reagents were from Sigma unless indicated otherwise.

Macrophage cell invasion assay. The gentamicin-protection assay (Elsinghorst, 1994), as modified by Burns et al. (1996), was used to quantify intracellular bacteria. PU5-1.8 macrophages were seeded at a density of $7 \cdot 5 \times 10^{5}$ cells per well and allowed to grow overnight. Bacteria grown to mid-exponential phase were washed, diluted in tissue culture medium, and then added to macrophages at an m.o.i. of $1-5$ bacteria per macrophage. Infected monolayers were centrifuged at $500 \mathrm{~g}$ for $5 \mathrm{~min}$ and incubated for $2 \mathrm{~h}$ at $37^{\circ} \mathrm{C}$ in $5 \% \mathrm{CO}_{2}$, followed by three washes with PBS to remove non-ingested extracellular bacteria. Fresh medium containing $1 \mathrm{mg}$ ceftazidime $\mathrm{ml}^{-1}$ and $500 \mu \mathrm{g}$ kanamycin $\mathrm{ml}^{-1}$ was added to kill the remaining extracellular bacteria, and cultures were incubated for another $2 \mathrm{~h}$. At this time, antibiotics were removed by washing with PBS, and an aliquot from the final wash was plated to determine the number of any remaining extracellular bacteria. Macrophages were lysed by adding Triton X-100 to a $1 \%$ $(\mathrm{v} / \mathrm{v})$ final concentration. Lysates were serially diluted and plated following the procedure described by Jett et al. (1997). The number of intracellular bacteria was calculated from the difference between colony counts in the PBS wash and those in 

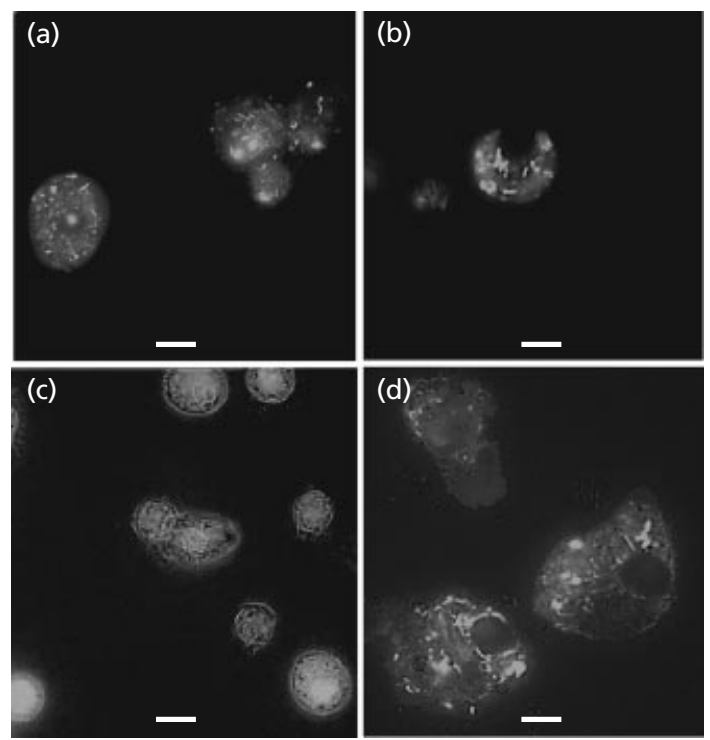

Fig. 1. Acridine orange-crystal violet staining of infected macrophages. PU5-1.8 cells were infected with E. coli HB101 (a, c) or B. cepacia CEP021 (b, d) and observed at $24 \mathrm{~h}(\mathrm{a}, \mathrm{b})$ and $72 \mathrm{~h}(\mathrm{c}, \mathrm{d})$ post-infection. Bacteria were added for $2 \mathrm{~h}$ and then treated with antibiotics (see Methods). $25 \mu \mathrm{g}$ kanamycin $\mathrm{ml}^{-1}$ was added to the cultures in long-term incubation experiments. At the times indicated, cells were stained with acridine orange and observed under the fluorescence microscope. Bar in $a, b$ and $c, 10 \mu \mathrm{m}$; bar in $\mathrm{d}, 6 \mu \mathrm{m}$.

the lysate. For long-term incubation experiments, parallel sets of cultures were maintained with and without kanamycin $\left(25 \mu \mathrm{g} \mathrm{ml}^{-1}\right)$. In both cases, prior to sampling, cultures were treated with $1 \mathrm{mg}$ ceftazidime $\mathrm{ml}^{-1}$ and $500 \mu \mathrm{g}$ kanamycin $\mathrm{ml}^{-1}$ for $2 \mathrm{~h}$, to further minimize the number of extracellular bacteria recovered (Burns et al., 1996). At each time point, macrophages were removed from the dish by treatment with trypsin, counted and then lysed to quantify intracellular organisms as described above.

Fluorescence and electron microscopy. Infected and uninfected macrophages grown on coverslips were stained with acridine orange and counterstained with crystal violet as previously described by Miliotis (1991). Briefly, $1 \mathrm{ml} \mathrm{0 \cdot 01 \%}$ acridine orange solution in PBS was added to each well for 45 seconds. Wells were washed with PBS, followed by the addition of $1 \mathrm{ml} 0.05 \%$ crystal violet in $0.15 \mathrm{M} \mathrm{NaCl}$ for 1 min. After washing with PBS, coverslips were removed, inverted onto glass slides and the samples examined with a Zeiss Axioskop fluorescence microscope with excitation at $488 \mathrm{~nm}$ from an Argon-Helium laser. Vital staining with acridine orange is a sensitive method for detecting ingested bacteria and also allows differentiation between live and dead intracellular bacteria (Rost, 1995), as dead bacteria fluoresce red (metachromasy) and live bacteria fluoresce green (orthochromasy). Transmission electron microscopy was performed as previously described by Jones et al. (1996) and samples were visualized using a Phillips 300 transmission electron microscope located at the University of Guelph Scanning and Transmission Electron Microscope Facility.

Flow cytometry. Light scattering from PU5-1.8 cells infected with bacteria was used to determine the size of the cell population using flow cytometry (Salzman et al., 1990).
Infected cultures were incubated for $72 \mathrm{~h}$, after which time the macrophages were collected, washed in PBS and fixed overnight in $4 \%$ formaldehyde. Fixed cells were washed and resuspended in $300 \mu \mathrm{l}$ PBS. Flow cytometry was performed with a FACScan flow cytometer (Becton Dickinson) and the mean values of forward scatter (FSC), representing cell size, and side scatter (SSC), representing cell granularity, were determined utilizing CellQuest software.

Tumour necrosis factor (TNF) production. Live or heat-killed $\left(80^{\circ} \mathrm{C}\right.$ for $\left.30 \mathrm{~min}\right)$ bacteria were added to macrophage cultures at a ratio of 10 bacteria per macrophage. The levels of biologically active TNF in supernatants collected after the $2 \mathrm{~h}$ antibiotic treatment were determined by the use of a standard L929 killing assay (Martin \& Dorf, 1990). Supernatants from macrophages treated with $100 \mathrm{ng}$ LPS $\mathrm{ml}^{-1}$, which was prepared and purified in our laboratory from cultures of Shigella flexneri (Yao et al., 1992), were used as a positive control for TNF production. Each experiment was conducted in quadruplicate. Briefly, $1 \times 10^{4} \mathrm{~L} 929$ cells were seeded in each well of a 96 -well plate and incubated overnight at $37^{\circ} \mathrm{C}$ in $5 \%$ $\mathrm{CO}_{2}$. Fifty microlitres of macrophage supernatants (serially diluted in RPMI 1640) were added to L929 cell cultures, followed by the addition of $50 \mu \mathrm{l}$ RPMI 1640 medium containing $5 \mu \mathrm{g}$ actinomycin $\mathrm{D} \mathrm{ml}^{-1}$. Cultures were incubated for $18 \mathrm{~h}$ and the viability assessed using the modified MTT [3(4,5-dimethylthiazol-2-yl)2,5-diphenyltetrazolium bromide] assay as described by van de Loosdrecht et al. (1991). TNF- $\alpha$ activity in culture supernatants was quantified by comparison with standard murine recombinant TNF- $\alpha$, with $1 \mathrm{U}$ TNF- $\alpha$ being defined as the amount of TNF causing 50\% L929 cell death. To ascertain whether TNF- $\alpha$ induction was caused by B. cepacia LPS, experiments were conducted with polymyxin $\mathrm{B}$ (PMB), which was added to the macrophages at final concentrations of 5,50 and $100 \mu \mathrm{g} \mathrm{ml}^{-1} 1 \mathrm{~h}$ prior to infection.

Measurement of respiratory-burst activity. Priming of PU51.8 macrophages for superoxide release upon phorbol myristate acetate (PMA) stimulation following bacterial phagocytosis was determined by using the fluorescent probe dichlorofluorescein (DCF) and flow cytometry (Bass et al., 1983). This method is based on the metabolism of $2^{\prime}, 7^{\prime}$-dichlorofluorescin diacetate, which, after being taken up by macrophages, is subsequently hydrolysed by esterases to non-fluorescent, membrane impermeable DCF. Stimulation of the respiratory burst within cells results in the rapid oxidation of DCF to a fluorescent form by the action of peroxides in a process accelerated by the presence of intracellular peroxidases. Thus, DCF fluorescence is proportional to peroxide production. All reagents used in these experiments were obtained from Beckman-Coulter (CellProbe DCFH, PMA - Oxidative Burst). Macrophages were infected with bacteria at an m.o.i. of approximately 10 bacteria per macrophage, and treated with antibiotics as indicated above. Uninfected macrophages treated and untreated with $100 \mathrm{ng}$ S. flexneri $\mathrm{LPS} \mathrm{ml}^{-1}$, served as positive and negative controls, respectively. Macrophages were harvested at $36 \mathrm{~h}$ post-infection, and levels of superoxide release after $30 \mathrm{~min}$ following stimulation with PMA, as well as prior to stimulation, were determined by fluorescenceactivated cell sorting analysis. Experiments were also conducted with PMB as indicated above for determination of TNF.

Measurement of nitrite. Interferon gamma (IFN- $\gamma$ ) is known to prime macrophages to release $\mathrm{NO}$ upon further stimulation, increasing their microbicidal properties (Stuehr \& Marletta, $1985,1987)$. One set of macrophage cultures was treated with $50 \mathrm{U}$ IFN- $\gamma \mathrm{ml}^{-1} 24 \mathrm{~h}$ prior to infection. Live or heat-killed 

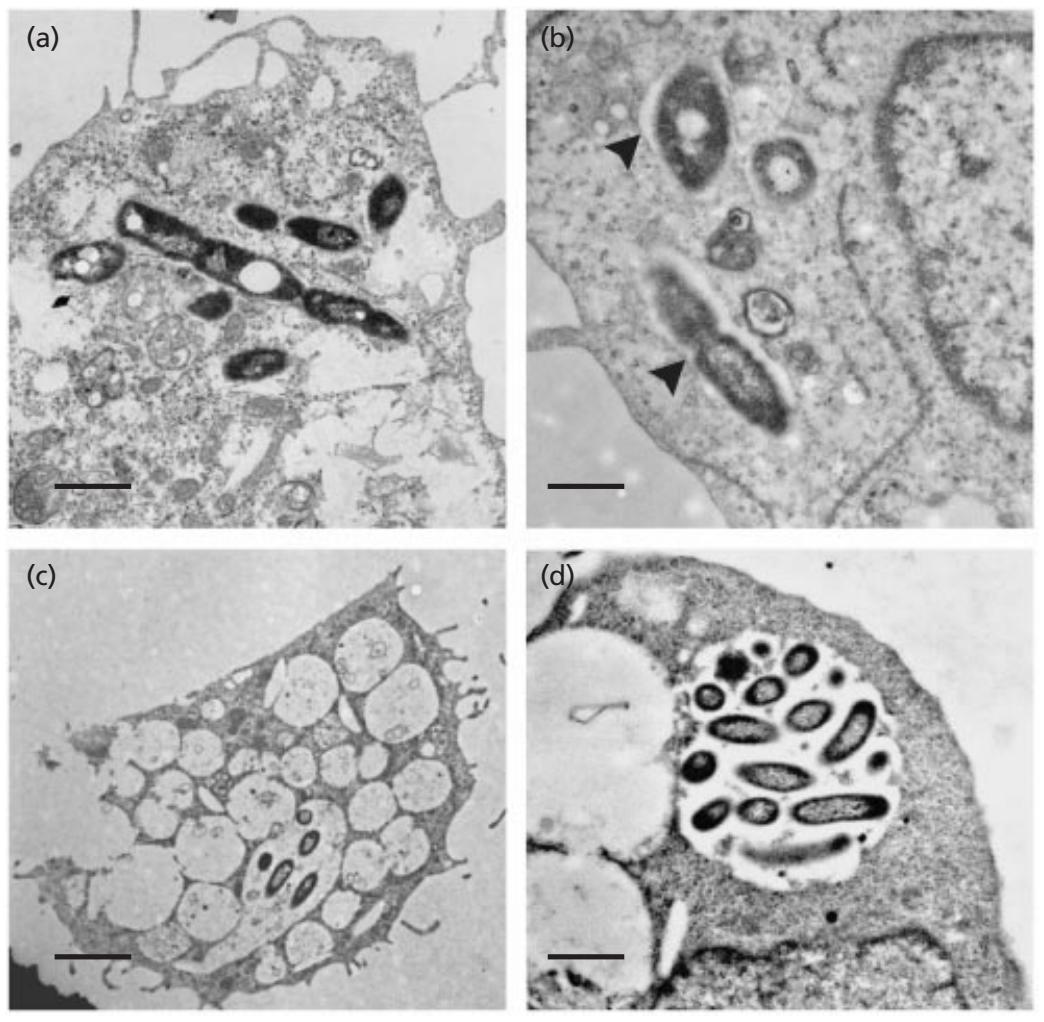

Fig. 2. Electron microscopy of macrophages containing intracellular B. cepacia CEP021. Ultrathin sections of PU5-1.8 macrophages $4 \mathrm{~h}(\mathrm{a}, \mathrm{b})$ and $24 \mathrm{~h}(\mathrm{c}, \mathrm{d})$ after entry of $B$. cepacia. Arrowheads in $b$ indicate the membrane boundary of the cytoplasmic vacuoles containing individual microorganisms. Large cytoplasmic vacuoles with and without bacteria are observed at $24 \mathrm{~h}$ (c). Bars, $1.6 \mu \mathrm{m}$ (a), $0.8 \mu \mathrm{m}$ (b), $5 \mu \mathrm{m}$ (c) and $1.9 \mu \mathrm{m}(\mathrm{d})$. bacteria were added to macrophage cultures at 10-20 bacteria per macrophage, followed by antibiotics as previously described. After the initial $2 \mathrm{~h}$ antibiotic treatment, macrophages were washed with Hank's balanced salt solution and the medium replaced with $200 \mu \mathrm{l}$ fresh medium containing $25 \mu \mathrm{g}$ kanamycin $\mathrm{ml}^{-1}$ and $100 \mu \mathrm{M}$ PTIO (2-phenyl-4,4,5,5-tetramethylimidazolin-1-oxyl 3-oxide; ICN). Nitrite production was determined using the Griess reagent as described by Amano \& Noda (1995). Absorbance was measured at $540 \mathrm{~nm}$ using an ELISA plate reader spectrophotometer, and nitrite concentrations were quantified from a standard curve with $\mathrm{NaNO}_{3}$. NO production by IFN- $\gamma$-primed macrophages treated with LPS was determined as a positive control.

Statistics. Data were analysed by single factor ANOVA. Results were considered significant at $P<0 \cdot 01$.

\section{RESULTS}

\section{B. cepacia CEP021 and B. vietnamiensis CEP040 survive within PU5-1.8 macrophages}

Removal of extracellular bacteria was an obligatory step prior to the quantification of intracellular bacteria. Thus, we used B. cepacia complex strains susceptible to antibiotics that do not penetrate the macrophage cell membrane, such as ceftazidime and kanamycin. We found that the majority of genomovar III isolates examined were resistant to $500 \mu \mathrm{g}$ ceftazidime $\mathrm{ml}^{-1}$ and all aminoglycosides tested, making it impossible to assess their intracellular survival. In contrast, B. cepacia CEP021 and B. vietnamiensis CEP040 were sensitive to $100 \mu \mathrm{g}$ ceftazidime $\mathrm{ml}^{-1}$ and $100 \mu \mathrm{g}$ kanamycin $\mathrm{ml}^{-1}$. A similar combination of antibiotics has been used pre- viously by Burns et al. (1996) to show entry and intracellular replication of strain CEP040 in epithelial cells. Also, we have recently shown that strains CEP021 and CEP040 can survive intracellularly within Acanthamoeba (Marolda et al., 1999). Therefore, both bacterial strains were used in the experiments described in this study.

The PU5-1.8 macrophage cell line was chosen based on a previous report indicating that these cells possess immunocytochemical characteristics of mature macrophages (Nibbering \& Van Furth, 1988). Phagocytosis and intracellular survival of CEP021 was followed using acridine orange-crystal violet staining. As a control, macrophages were infected with E. coli

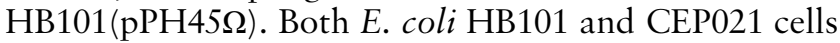
were visible within the cytoplasm of infected macrophages at $2 \mathrm{~h}$ and $24 \mathrm{~h}$ post-infection (Fig. 1a, b). At these times, $3-5 \%$ of macrophages were infected with either CEP021 or E. coli. At $48 \mathrm{~h}$ and $72 \mathrm{~h}$ postphagocytosis, E. coli HB101 cells were no longer visible within infected macrophages (Fig. 1c), suggesting that intracellular bacteria were killed and degraded. In contrast, CEP021 cells remained clearly visible as clusters of cells and also as individual bacteria scattered within the cytoplasm (Fig. 1d). A few bacteria were dead, as they displayed red fluorescence, but the great majority (more than $80 \%$ ) exhibited green fluorescence, indicating they were still viable. This was supported by the fact that intracellular B. cepacia were highly motile, suggesting that they remained metabolically active. In some experiments, the observation period was extended 
Table 1. Kinetics of invasion of PU5-1.8 macrophages by CEP021

Tenfold dilutions of bacterial inoculum ranging from $9 \times 10^{3}$ to $9 \times 10^{7}$ bacteria were used with $10^{6}$ macrophages per well. Macrophages were incubated with bacteria for $2 \mathrm{~h}$ and then treated for another $2 \mathrm{~h}$ with ceftazidime and kanamycin as indicated in Methods. The experiment was done in triplicate. The number of intracellular bacteria was calculated from the subtraction of extracellular bacteria from the total bacteria recovered after lysis of macrophages.

\begin{tabular}{|lll|}
\hline $\begin{array}{l}\text { Bacterial } \\
\text { inoculum }\end{array}$ & m.o.i. & Intracellular bacteria $\pm \mathrm{SD}^{*}$ \\
\hline $9 \times 10^{3}$ & $0 \cdot 009$ & $2 \cdot 01 \times 10^{3} \pm 0 \cdot 51 \times 10^{3}(22 \cdot 2)$ \\
$9 \times 10^{4}$ & $0 \cdot 09$ & $6 \cdot 48 \times 10^{3} \pm 0 \cdot 32 \times 10^{3}(7 \cdot 2)$ \\
$9 \times 10^{5}$ & $0 \cdot 9$ & $2 \cdot 92 \times 10^{4} \pm 0 \cdot 96 \times 10^{4}(3 \cdot 2)$ \\
$9 \times 10^{6}$ & 9 & $5 \cdot 80 \times 10^{5} \pm 0 \cdot 76 \times 10^{5}(6 \cdot 4)$ \\
$9 \times 10^{7}$ & 90 & $1 \cdot 82 \times 10^{6} \pm 0 \cdot 53 \times 10^{6}(2)$ \\
\hline
\end{tabular}

* Numbers in parentheses indicate the percentage of the inoculum recovered as intracellular bacteria.

to $96 \mathrm{~h}$ and $120 \mathrm{~h}$, with similar results. Therefore, we concluded that B. cepacia CEP021 resisted macrophage bactericidal mechanisms and thus survived intracellularly for a prolonged period of time. Pretreatment of macrophages with cytochalasin $\mathrm{D}$ reduced bacterial internalization to less than $0.25 \%$ with respect to untreated controls. Internalization of bacteria was largely unaffected when macrophages were pretreated with colchicine (data not shown). Thus, internalization of B. cepacia CEP021 by macrophages was due to microfilament-dependent phagocytosis. Neither cytochalasin D nor colchicine at the concentrations used had any apparent effect on the viability of B. cepacia CEP021. Phagocytosis experiments were also conducted in the absence of serum, and no differences were observed in the percentage of infected macrophages as compared to controls, suggesting that entry of B. cepacia CEP021 into PU5-1.8 macrophages does not require opsonization with serum. Similar results were obtained using a macrophage cell line of different lineage, J774A.1, demonstrating that bacterial survival within macrophages was not restricted to PU5-1.8 cells. Identical results were obtained with the $B$. vietnamiensis strain CEP040, indicating that intracellular survival can be demonstrated in members of at least two genomovars of the $B$. cepacia complex.

Infected macrophages were analysed by electron microscopy. At $2 \mathrm{~h}$ post-infection, individual bacteria were localized within membrane-bound vacuoles (Fig. 2a, b). At $24 \mathrm{~h}$ post-infection, large vacuoles were present in the cytoplasm of infected macrophages, but only some of them contained multiple bacterial cells (Fig. 2c, d). Similar observations were made in control experiments using heat-killed micro-organisms (data not shown), suggesting the possibility that vacuoles harbouring multiple bacteria arise from the fusion of phagocytic

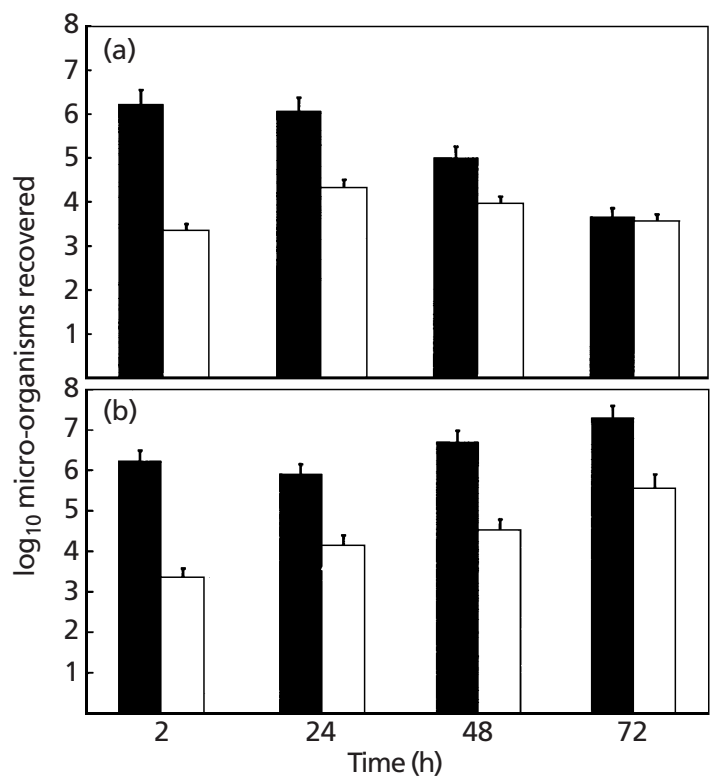

Fig. 3. Quantification of intracellular bacteria in long-term incubations. After $2 \mathrm{~h}$ infection with CEP021, PU5-1.8 macrophages were treated with kanamycin and ceftazidime for $2 \mathrm{~h}$. Fresh medium with $25 \mu \mathrm{g}$ kanamycin $\mathrm{ml}^{-1}$ (a) or without kanamycin (b) was added and incubations continued for 24, 48 and $72 \mathrm{~h}$. Both intracellular (black bars) and extracellular (white bars) micro-organisms were quantified at 2, 24, 48 and $72 \mathrm{~h}$ following the standard $2 \mathrm{~h}$ incubation with ceftazidime and kanamycin (see Methods). Error bars represent the standard error of three values.

vacuoles that initially contained individual microorganisms, rather than from the intracellular replication of membrane-bound bacterial cells.

\section{Quantification of intracellular bacteria}

To further elucidate whether intracellular replication occurs we used a modified antibiotic protection assay (Burns et al., 1996). A combination of $1 \mathrm{mg}$ ceftazidime $\mathrm{ml}^{-1}$ and $500 \mu \mathrm{g}$ kanamycin $\mathrm{ml}^{-1}$ was used to kill extracellular bacteria in all invasion experiments. Table 1 reveals that as the inoculum size increased, the number of recovered intracellular bacteria also increased. Based on these results, we standardized the bacterial inoculum to approximately $10^{6}$ micro-organisms per $\mathrm{ml}$, and used an m.o.i. of 1-10 bacteria per macrophage. Under these conditions, extracellular bacteria represented less than $6 \%$ of the total bacteria recovered from the cell lysate. During long-term incubation experiments in the presence of kanamycin, the levels of extracellular bacteria remained roughly constant, indicating that the antibiotic prevented the growth of residual extracellular bacteria. This was confirmed by the lack of visible extracellular bacteria as determined by direct microscopic observation of infected cultures. However, over the course of $72 \mathrm{~h}$, the number of intracellular bacteria decreased by $\sim 3 \log$ units, strongly suggesting that there is no intracellular bacterial replication (Fig. 3a). It is possible that during long-term incubations, the antibiotic can 

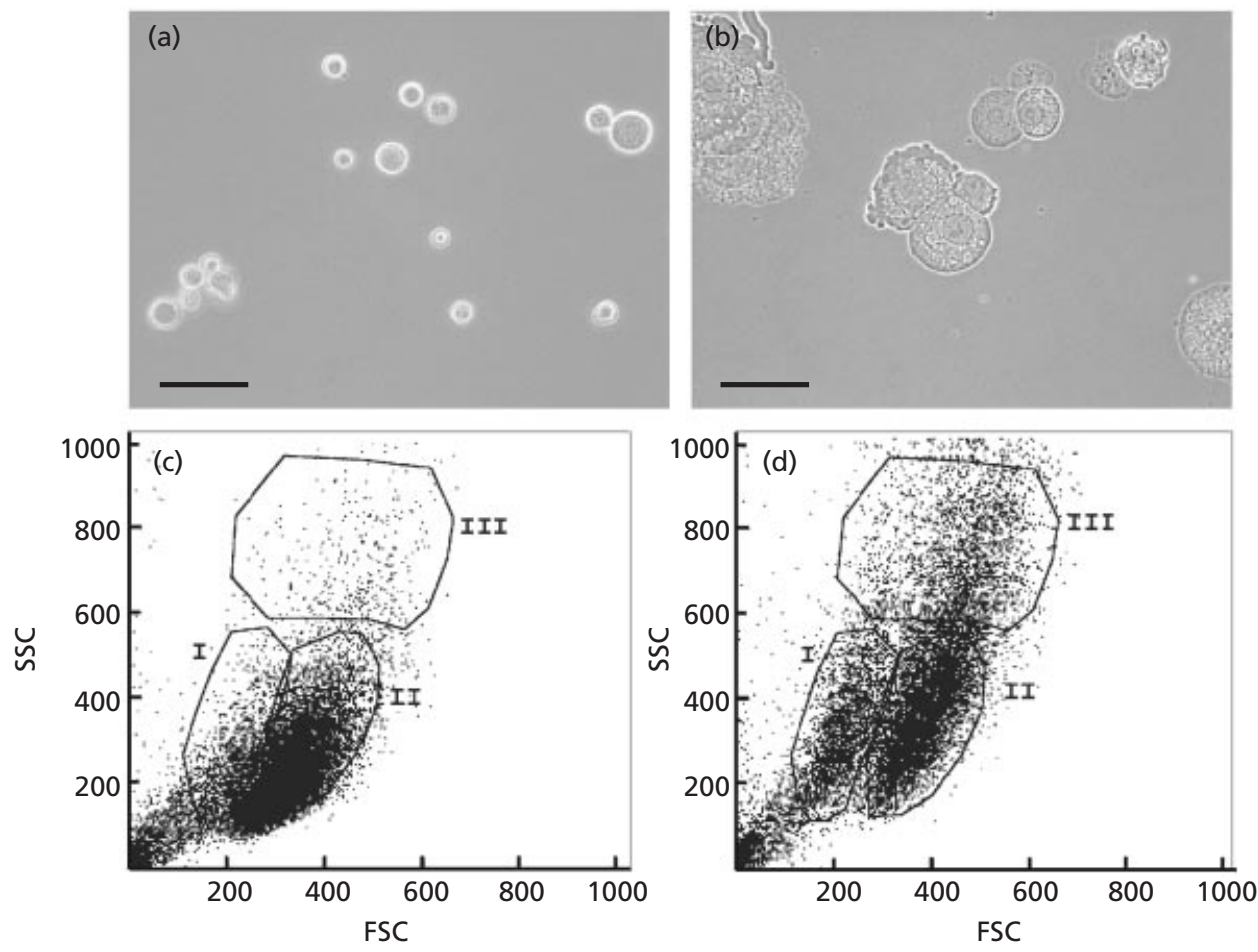

$X=231 \cdot 7 \pm 1 \cdot 3$

$X=265 \cdot 8 \pm 0 \cdot 7$

$Y=203 \cdot 6 \pm 15 \cdot 0$

$\mathrm{Y}=351 \cdot 1 \pm 10 \cdot 0$

Fig. 4. Bacterial infection alters the morphology of PU5-1.8 cells. CEP021-uninfected (a) and -infected (b) PU5-1.8 macrophages were examined by light microscopy $72 \mathrm{~h}$ post-infection. Macrophages from cultures exposed to $B$. cepacia (b) were larger and displayed a granular cytoplasm. Bars, $34 \mu \mathrm{m}$. Light scatter analysis of PU5-1.8 macrophage cells uninfected (c) and infected (d) with B. cepacia at $72 \mathrm{~h}$ shows that infected cultures have a heterogeneous population of cells. The results are displayed as a dual parameter dot plot of forward (FSC) and perpendicular (SSC) light Scatter. Each dot represents a single cell and the dot coordinates reflect its scatter intensities. I, II and III indicate the main regions of light scatter intensities. Mean and standard error of FSC (X) and SSC (Y) values for uninfected (c) and infected (d) macrophages are indicated below the graphs.

penetrate macrophages and prevent growth of intracellular bacteria. For this purpose, we also conducted phagocytosis experiments without antibiotic during long-term incubations. In these cases, microscopic examination of cultures at $2 \mathrm{~h}$ and $24 \mathrm{~h}$ post-infection revealed no extracellular bacteria, but by $48 \mathrm{~h}$ and $72 \mathrm{~h}$, extracellular bacteria were readily visible. Fig. 3 (b) shows that between $2 \mathrm{~h}$ and $72 \mathrm{~h}$, the number of intracellular bacteria increased 12 -fold (1.1 log units), while extracellular bacteria increased 157 -fold ( $2 \cdot 2 \mathrm{log}$ units). Extracellular bacteria never represented more than $1.8 \%$ of the total bacteria recovered at any given time point, suggesting that greater than $98 \%$ of the total bacteria recovered were of intracellular origin. However, the presence of extracellular bacteria in the tissue culture medium, especially at $48 \mathrm{~h}$ and $72 \mathrm{~h}$ postinfection, indicates that the initial antibiotic treatment did not efficiently kill all extracellular bacteria. Similar observations were made by Burns et al. (1996) with strain CEP040 in the epithelial cell line A549. Conceivably, extracellular bacteria escaping killing by antibiotics administered at the beginning of the experiment may enter the macrophages at later times, and contribute to the intracellular fraction recovered at $48 \mathrm{~h}$ and $72 \mathrm{~h}$.
Thus, the apparent increase in the number of intracellular bacteria is most likely an artefact due to the presence of residual extracellular bacteria not effectively killed by the initial treatment with ceftazidime and kanamycin. From all these experiments, we conclude that intracellular bacteria do not replicate, although it is not possible to rule out a low level of replication. In a control phagocytosis assay using the intracellular pathogen Lis. monocytogenes, we detected more than two doublings in intracellular micro-organisms over the course of a $6 \mathrm{~h}$ invasion experiment (data not shown), demonstrating that PU5-1.8 macrophages can support the replication of intracellular bacteria.

\section{Bacterial infection causes activation of macrophages}

Under our experimental conditions, the viability of macrophages at the various time points during phagocytosis assays exceeded $95 \%$, as determined by trypan blue exclusion. However, following bacterial infection macrophages appeared to undergo morphological changes involving enlargement of the cytoplasm and vacuolization (Fig. 4a, b). At $96 \mathrm{~h}$ and $120 \mathrm{~h}$ after phagocytosis, most of the cells were floating in the 

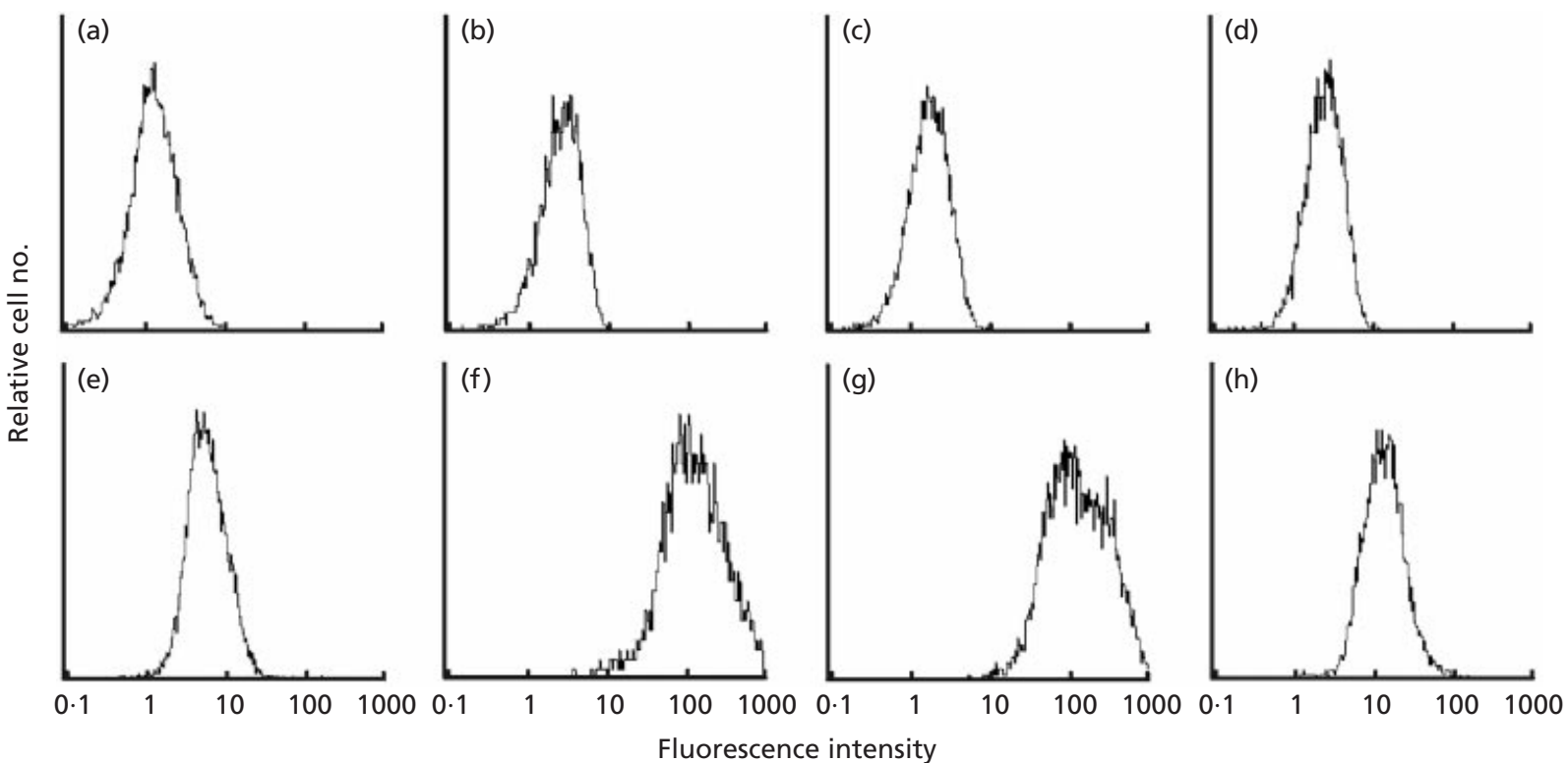

Fig. 5. Flow cytometry analysis to determine the formation of superoxide by macrophage cell cultures. The graphs show the fluorescence distribution of DCF oxidation prior to (a-d) and $30 \mathrm{~min}$ after (e-h) stimulation with PMA. The abscissa represents the macrophage cell fluorescence intensity on a logarithmic scale (arbitrary units). The experiment included untreated macrophages $(a, e), B$. cepacia-infected macrophages $(b, f)$, LPS-treated macrophages $(c, g)$ and $B$. cepaciainfected macrophages pre-treated with PMB $(d, h)$.

culture medium and only a few cells remained adhered to the bottom of the dishes. The morphological changes occurred in both infected as well as uninfected cells in the same culture dish, and were best assessed by fluorescence-activated cell sorting analysis. The macrophage cell population exposed to B. cepacia CEP021 for $72 \mathrm{~h}$ appeared to be heterogeneous, as indicated by the side scatter values represented by regions I, II and III, which corresponded to $13.3 \%, 31 \cdot 6 \%$ and $13.0 \%$ of cell counts, respectively (Fig. 4d). In contrast, uninfected cell cultures incubated for the same time remained relatively homogeneous (Fig. 4c). Cell counts for regions I, II and III corresponded to $8 \cdot 0 \%, 46.5 \%$ and $1.7 \%$, respectively. These results correlated well with microscopic observations and suggested that infection of PU5-1.8 cells with B. cepacia CEP021 is associated with dramatic alterations in the physical properties of the macrophage, possibly due to cell activation.

Activated macrophages are known to produce a number of cytokines including TNF- $\alpha$ (Wewers, 1997). Thus, we investigated production of TNF- $\alpha$ by PU5-1.8 macrophages infected with bacteria as a marker for cell activation. The concentration of TNF- $\alpha$ in macrophage culture supernatants $2 \mathrm{~h}$ post-phagocytosis was determined using a bioassay based on the killing of TNF- $\alpha$ sensitive L929 cells. A basal level of 0.04 \pm 0.009 U TNF$\alpha$ was spontaneously produced by PU $5-1.8$ macrophages, as previously reported for this cell line (Biragyn \& Nedospasov, 1995). However, following treatment with LPS, PU5-1.8 cells produced and released significantly more TNF- $\alpha$ than untreated macrophages $(3 \cdot 36 \pm 1 \cdot 147$ $\mathrm{U}, P<0 \cdot 01)$. Culture supernatants of macrophages exposed to live bacteria had a significantly higher amount of TNF- $\alpha(67 \cdot 48 \pm 4 \cdot 18 \mathrm{U}, P<0 \cdot 01)$ than supernatants of untreated macrophages. In contrast, heatkilled bacteria did not induce higher levels of TNF- $\alpha$ than those found following stimulation with LPS alone $(5.94 \pm 0.640 \mathrm{U})$, suggesting that production of TNF- $\alpha$ required viable bacteria. It has been shown by other investigators that ceftazidime causes release of biologically active LPS from the bacterial outer membrane (Dofferhoff et al., 1993; Kirikae et al., 1998). Therefore, to determine whether LPS was involved in TNF- $\alpha$ production, we conducted inhibition studies using PMB. PMB binds to the lipid A component of the LPS molecule, thereby preventing its interaction with its receptor and thus inhibiting TNF- $\alpha$ production (Lasfargues et al., 1989). Treatment with PMB at concentrations of 5,50 and $100 \mu \mathrm{g} \mathrm{m}^{-1}$ prior to infection of macrophages reduced TNF- $\alpha$ production by 50,75 and $85 \%$, respectively. Thus, we concluded that soluble LPS released by live bacteria is involved in the stimulation of macrophages following bacterial infection.

Activated macrophages also produce reactive oxygen species and nitrogen intermediates (Granger et al., 1990; Guthrie et al., 1984) that contribute to the killing of phagocitized bacteria. In a previous study, it has been shown that oxidative killing is an important component of the macrophage bactericidal activity against $B$. cepacia complex isolates (Speert et al., 1994). Since our microscopic studies indicated that B. cepacia CEP021, but not the E. coli control, survive within macrophages for at least $72 \mathrm{~h}$, it was important to determine whether survival occurs in the presence of bactericidal oxygen 
Table 2. Nitrite production by PU5-1.8 macrophages

\begin{tabular}{|lcc|}
\hline Treatment* & $\begin{array}{c}\text { Nitrite } \\
\text { concentration } \\
(\boldsymbol{\mu M}) \pm \text { SD } \dagger\end{array}$ & $\begin{array}{c}\text { Induction } \\
\text { factor }\end{array}$ \\
\hline None & $7 \cdot 42 \pm 0 \cdot 83$ & 1 \\
IFN- $\gamma$ & $76 \cdot 5 \pm 4 \cdot 26$ & $10 \cdot 33$ \\
LPS & $8 \cdot 2 \pm 1 \cdot 88$ & $1 \cdot 1$ \\
IFN- $\gamma$ + LPS & $110 \cdot 76 \pm 5 \cdot 37$ & $14 \cdot 8$ \\
Live bacteria & $8 \cdot 65 \pm 0 \cdot 49$ & $1 \cdot 1$ \\
IFN- $\gamma$ + live bacteria & $52 \cdot 65 \pm 2 \cdot 84$ & $7 \cdot 1$ \\
Heat-killed bacteria & $8 \cdot 88 \pm 0 \cdot 37$ & $1 \cdot 1$ \\
IFN- $\gamma$ + heat-killed bacteria & $79 \cdot 65 \pm 5 \cdot 06$ & $10 \cdot 7$ \\
\hline
\end{tabular}

*IFN- $\gamma$ pre-treated and untreated macrophages were exposed to heat-killed or live B. cepacia CEP021 cells. Macrophages were also treated with LPS to determine the maximum production of nitric oxide. Data were collected $24 \mathrm{~h}$ after phagocytosis or treatment with LPS.

†Culture supernatants were assayed for nitrite concentration using the Griess reagent. Data shown represent the mean and standard error of 8 experiments.

and nitrogen intermediates. LPS primes macrophages for enhanced release of superoxide in response to other stimuli such as PMA or $\mathrm{N}$-formylated bacterial peptides (Guthrie et al., 1984; Vosbeck et al., 1990). Thus, superoxide ion production was investigated by treating infected macrophage cultures with PMA. Macrophage cultures either infected with bacteria or treated with purified LPS showed enhanced production of superoxide when stimulated with PMA (Fig. 5f, g). In contrast, macrophage cultures treated with bacteria in the presence of PMB showed much less superoxide production (Fig. 5h), suggesting released LPS is the primary mechanism involved in the ability of $B$. cepacia to prime macrophages for superoxide production. This conclusion is in agreement with previous observations by other groups indicating that B. cepacia LPS is a potent inducer of phagocytes (Hughes et al., 1997; Smith et al., 1999).

To examine whether phagocytosis of B. cepacia is associated with production of nitric oxide, we measured the levels of nitrite in supernatants from infected and uninfected macrophages. In this case, macrophages were primed with IFN- $\gamma$. Irrespective of the stimulus, in the absence of priming by IFN- $\gamma$ the concentration of nitrite produced by macrophage cultures was very low and virtually identical to the basal level spontaneously produced by untreated cells (Table 2). In contrast, nitrite production with IFN- $\gamma$ pre-stimulation and LPS treatment increased 10- and 14-fold with respect to basal levels (Table 2). Priming with IFN- $\gamma$ followed by exposure to heat-killed bacteria resulted in nitrite levels similar to those observed with IFN- $\gamma$ alone, suggesting that inactivated bacteria do not stimulate any further increase in NO synthesis. In contrast, infection of primed macrophages with live B. cepacia CEP021 resulted in a significantly lower nitrite production than that attributed to IFN- $\gamma$ alone $(P<0 \cdot 01)$, which suggests that $B$. cepacia infection may interfere with the levels of nitrite. Since under the experimental conditions used, live B. cepacia release LPS, and LPS enhances the levels of measured nitrite (Table 2), we attributed the observed decrease to either inhibition of the NO synthesis pathway or utilization of nitrite by metabolically active intracellular bacteria.

\section{DISCUSSION}

\section{B. cepacia can survive intracellularly in the absence of significant bacterial replication}

We report in this study that two isolates of the B. cepacia complex can survive within the murine macrophages cell line PU5-1.8 for a period of several days. Direct observations with fluorescence and electron microscopy indicate that $B$. cepacia CEP021, B. vietnamiensis CEP040 and the E. coli control entered PU5-1.8 macrophage cells, but only B. cepacia and B. vietnamiensis remained detectable $3 \mathrm{~d}$ after infection. This is in accordance with previously reported results (Caron et al., 1994), indicating that survival of E. coli K-12 in U937 macrophages was limited to a maximum of $3 \mathrm{~d}$. Several observations support the conclusion that intracellular $B$. cepacia CEP021 and B. vietnamiensis CEP040 cells are viable: i) bacteria within vacuoles were highly motile, even in some experiments where observations were extended to $120 \mathrm{~h}$, suggesting they are metabolically active; ii) more than $80 \%$ of the intracellular bacteria displayed green fluorescence with acridine orange; iii) micro-organisms were recovered by culture after lysis of infected macrophages in the absence of extracellular bacteria, as observed microscopically. Therefore, we were able to show that B. cepacia CEP021 and B. vietnamiensis CEP040, but not E. coli HB101, are capable of long-term intracellular survival in a murine macrophage-derived cell line.

Experiments to demonstrate intracellular replication by the use of the kanamycin/ceftazidime protection assay consistently showed that in the presence of kanamycin during long-term incubations, there was a progressive decrease in the number of viable bacteria recovered over the course of $72 \mathrm{~h}$. Several groups working with other micro-organisms such as Rhodococcus equi (Hondalus \& Mosser, 1994), Klebsiella pneumoniae (Oelschlaeger \& Tall, 1997) and Mycobacterium tuberculosis (Mehta et al., 1996) have reported a continual decrease in recovered intracellular bacteria despite microscopic observations suggesting bacterial replication. Although aminoglycoside antibiotics are generally thought to be unable to penetrate eukaryotic cell membranes, several studies show they can enter macrophages and inactivate intracellular bacteria (Crowle et al., 1984; Drevets et al., 1994). It has also been proposed that toxicity due to growth of intracellular bacteria causes alterations of the eukaryotic cell membrane, thereby increasing its permeability to antibiotics in the medium (Hondalus \& Mosser, 1994). Furthermore, bacterial infection with $B$. cepacia complex strains could cause macrophage cell 
lysis and release of intracellular bacteria into the medium. These micro-organisms would be subsequently killed by the extracellular kanamycin and thus, despite their intracellular origin, they would not contribute to the recovered intracellular pool of bacteria. A recent study has reported that a purified lipopeptide produced by a genomovar III strain under very strict growth conditions in vitro induces apoptosis in neutrophils (Hutchinson et al., 1998). We were unable to demonstrate apoptosis in PU5-1.8 macrophages infected with the genomovar VI strain CEP021 and the $B$. vietnamiensis strain CEP040 (data not shown). However, the growth conditions used in these experiments are different than those of Hutchinson et al. (1998).

Increasing bacterial cell numbers, as early as $48 \mathrm{~h}$ after incubation, were observed in the absence of kanamycin. This experimental protocol was the same as the one used by Burns et al. (1996) to infect epithelial cells with B. vietnamiensis CEP040. Under these conditions, we observed only a $1.1 \log$ increase of intracellular bacteria over a period of $72 \mathrm{~h}$. This represents a small increase compared with bacterial growth in culture without macrophages, where the micro-organisms reach several log units within 24-36 h (Marolda et al., 1999). In a previous study of intracellular survival of $B$. cepacia complex strains (including CEP021 and CEP040) within amoebae, we have reported a similarly small increase in the number of intracellular bacteria and demonstrated that the principal mechanism of bacterial replication is extracellular (Marolda et al., 1999). Although in the long-term phagocytosis assays, extracellular bacteria represented no more than $1.8 \%$ of the total number of recovered bacteria, the small increase in intracellular micro-organisms could be explained by phagocytosis of bacteria undergoing replication that fail to initiate new replication cycles once they become intracellular. Taken together, our results suggest that our B. cepacia complex isolates do not replicate intracellularly in phagocytic cells, and caution is warranted when interpreting invasion experiments with $B$. cepacia complex strains using other cell systems.

\section{Presence of intracellular $B$. cepacia is associated with macrophage cell activation}

The change in physical size of infected macrophages, as observed by light microscopy, suggested that they might be activated. Macrophage activation, along with physical cell changes, leads to up-regulation of major histocomaptibility complex class II antigens and accessory molecules such as B7.1, as well as production of various cytokines, including TNF- $\alpha$ and interleukin-8. Our studies suggested that live B. cepacia complex strains primed PU5-1.8 cells to produce TNF- $\alpha$ and superoxide. Released LPS mediated these effects, since they were inhibited by PMB, and a much lower level of stimulation was observed with heat-killed bacteria. Release of LPS from bacteria may be a consequence of antibiotic treatment with ceftazidime. Other investigators have documented significant levels of biologically active LPS in the medium of cultures of $P$. aeruginosa and E. coli incubated with ceftazidime (Dofferhoff et al., 1993; Kirikae et al., 1998). A similar situation may occur in the CF patient, where LPS release following antibiotic treatment, in conjunction with the ability of $B$. cepacia complex strains to remain viable after phagocytosis, may contribute to an enhanced inflammatory response and progression of lung disease.

NO, produced by the nitric oxide synthase, has been identified as the effector molecule for killing a range of intracellular pathogens (Lowenstein et al., 1994; Summersgill et al., 1992). When primed with IFN- $\gamma$ for $24 \mathrm{~h}$ prior to infection, macrophages exposed to heatkilled bacteria yielded nitrite levels similar to those obtained with PU5-1.8 cells treated with IFN- $\gamma$ alone. Although this could be due to a lack of LPS release by heat-killed bacteria, other possibilities should be considered. Previous studies suggested that only phagocytosis of opsonized micro-organisms can engage the intracellular signalling pathways necessary for NO production (Gross et al., 1998). Since we have shown that serum does not appear to be required for B. cepacia CEP021 entry into PU5-1.8 macrophages, lack of NO induction could be explained by bacterial entry via a non-opsonic mechanism. The decreased level of nitrite found in macrophages exposed to live B. cepacia CEP021 was unexpected, since we have shown that under our experimental conditions live bacteria release LPS, which in turn stimulates NO production. It is possible that following phagocytosis, B. cepacia complex isolates may induce the production of immunomodulatory molecules, such as prostaglandins, that downregulate NO synthesis (D'Acquisto et al., 1998; Venkataprasad et al., 1996), or alternatively, live micro-organisms utilize nitrate. Utilization of nitrate by $B$. cepacia has been previously documented (Gessner \& Mortensen, 1990).

In summary, the results presented in this work, together with those of a previous report (Marolda et al., 1999) indicate that $B$. cepacia complex isolates can survive intracellularly within phagocytic cells. More importantly, survival takes place in the presence of macrophage activation, especially superoxide release. Although a previous report indicated that B. cepacia complex isolates can be killed by oxidative mechanisms while resisting non-oxidative damage (Speert et al., 1994), our data suggest that resistance to oxidation may play a role in survival of intracellular bacteria. Both catalase and superoxide dismutase are important for detoxifying toxic oxidants from cells (Hassett \& Cohen, 1989). We are currently examining their occurrence and characteristics in isolates of the $B$. cepacia complex in relation to intracellular survival (M. D. Lefebre \& M. A. Valvano, unpublished). In the context of the pathogenesis of CF lung infection, our data suggest a model whereby B. cepacia complex strains can resist phagocytic killing, while LPS released from invading microorganisms (either spontaneously or after antibiotic treatment) at the site of infection may sensitise local phagocytic cells to amplify the inflammatory response. It has been shown by other investigators that $B$. cepacia 
LPS is more pro-inflammatory than LPS of $P$. aeruginosa (Hughes et al., 1997; Shaw et al., 1995; Zughaier et al., 1999). Since this amplified response may fail to clear the infection by $B$. cepacia, the inflammation will perpetuate itself with subsequent cycles of phagocytosis and activation of macrophages, resulting in progressive lung tissue damage.

\section{ACKNOWLEDGEMENTS}

We are grateful to M. Keeney and W. Brown (Flow Cytometry, London Health Sciences Centre) for assistance with the measurement of the oxygen burst in macrophages, $T$. Beveridge and D. Moyles (Department of Microbiology, University of Guelph) for help with the electron microscopy, B. Rider and R. Mukerjee (Department of Microbiology and Immunology, University of Western Ontario) for assistance with cell lines and G. Strejan (Department of Microbiology and Immunology, University of Western Ontario) for the gift of IFN $-\gamma$. This research was supported in part by an Internal Research Grant of the London Health Sciences Centre to M.A.J. and M.A.V.

\section{REFERENCES}

Amano, F. \& Noda, T. (1995). Improved detection of nitric oxide radical $\left(\mathrm{NO}^{*}\right)$ production in an activated macrophage culture with a radical scavenger, carboxy PTIO, and Griess reagent. FEBS Lett 368, 425-428.

Bals, R., Weiner, D. J. \& Wilson, J. M. (1999). The innate immune system in cystic fibrosis lung disease. J Clin Invest 103, 303-307.

Bass, D. A., Parce, J. W., Dechatelet, L. R. P. S., Seeds, M. C. \& Thomas, M. (1983). Flow cytometric studies of oxidative product formation by neutrophils: a graded response to membrane stimulation. J Immunol 130, 1910-1917.

Biragyn, A. \& Nedospasov, S. A. (1995). Lipopolysaccharideinduced expression of TNF- $\alpha$ gene in the macrophage cell line ANA-1 is regulated at the level of transcription processivity. $J$ Immunol 155, 674-683.

Brown, M. R. W. \& Barker, J. (1999). Unexplored reservoirs of pathogenic bacteria: protozoa and biofilms. Trends Microbiol 7, 46-50.

Burns, J. L., Jonas, M., Chi, E. Y., Clark, D. K., Berger, A. \& Griffith, A. (1996). Invasion of respiratory epithelial cells by Burkholderia (Pseudomonas) cepacia. Infect Immun 64, 4054-4059.

Bye, M. R., Ewig, J. M. \& Quittell, L. M. (1994). Cystic fibrosis. Lung 172, 251-270.

Caron, E., Peyrard, T., Kohler, S., Cabane, S., Liautard, J. P. \& Dornand, J. (1994). Live Brucella spp. fail to induce tumour necrosis factor alpha excretion upon infection of U937-derived phagocytes. Infect Immun 62, 5267-5274.

Cheng, P. W., Boat, T. F., Cranfill, K., Yankaskas, J. R. \& Boucher, R. C. (1989). Increased sulfation of glycoconjugates by cultured nasal epithelial cells from patients with cystic fibrosis. J Clin Invest 84, 68-72.

Crowle, A. J., Sbarbaro, J. A., Judson, F. N., Douvas, G. S. \& May, M. H. (1984). Inhibition by streptomycin of tubercle bacilli within cultured human macrophages. Am Rev Respir Dis 130, 839-844.

D'Acquisto, F., Sautebin, L., luvone, T., Di Rosa, M. \& Carnuccio, R. (1998). Prostaglandins prevent inducible nitric oxide synthase protein expression by inhibiting nuclear factor-kappaB activation in J774 macrophages. FEBS Lett 440, 76-80.
Dofferhoff, A. S., Esselink, M. T., de Vries-Hospers, H. G., van Zanten, A., Bom, V. J., Weits, J. \& Vellenga, E. (1993). The release of endotoxin from antibiotic-treated Escherichia coli and the production of tumour necrosis factor by human monocytes. $J$ Antimicrob Chemother 31, 373-384.

Drevets, D. A., Canono, B. P., Leenen, P. J. \& Campbell, P. A. (1994). Gentamicin kills intracellular Listeria monocytogenes. Infect Immun 62, 2222-2228.

Elsinghorst, E. A. (1994). Measurement of invasion by gentamicin resistance. Methods Enzymol 236, 405-420.

FitzSimmons, S. (1996). United States cystic fibrosis foundation database. Bethesda, MD: Cystic Fibrosis Foundation.

Gessner, A. R. \& Mortensen, J. E. (1990). Pathogenic factors of Pseudomonas cepacia isolates from patients with cystic fibrosis. J Med Microbiol 33, 115-120.

Gilligan, P. H. (1991). Microbiology of airway disease in patients with cystic fibrosis. Clin Microbiol Rev 4, 35-51.

Govan, J. R. \& Deretic, V. (1996). Microbial pathogenesis in cystic fibrosis: mucoid Pseudomonas aeruginosa and Burkholderia cepacia. Microbiol Rev 60, 539-574.

Govan, J. R., Hughes, J. E. \& Vandamme, P. (1996). Burkholderia cepacia: medical, taxonomic and ecological issues. J Med Microbiol 45, 395-407.

Granger, D. L., Hibbs, J. B., Perfect, J. R. \& Durack, D. T. (1990). Metabolic fate of L-arginine in relation to microbiostatic capability of murine macrophages. J Clin Invest 85, 264-267.

Gross, A., Spiesser, S., Terraza, A., Rouot, B., Caron, E. \& Dornand, J. (1998). Expression and bactericidal activity of nitric oxide synthase in Brucella suis-infected murine macrophages. Infect Immun 66, 1309-1316.

Guthrie, L. A., McPhail, L. C., Henson, P. M. \& Johnston, R. B. (1984). Priming of neutrophils for enhanced release of oxygen metabolites by bacterial lipopolysaccharide: evidence for increased activity of the superoxide-producing enzyme. J Exp Med 160, 1656-1671.

Hassett, D. J. \& Cohen, M. S. (1989). Bacterial adaptation to oxidative stress: implications for pathogenesis and interaction with phagocytic cells. FASEB J 3, 2574-2582.

Hondalus, M. K. \& Mosser, D. M. (1994). Survival and replication of Rhodococcus equi in macrophages. Infect Immun 62, 4167-4175.

Hughes, J. E., Stewart, J., Barclay, G. R. \& Govan, J. R. (1997). Priming of neutrophil respiratory burst activity by lipopolysaccharide from Burkholderia cepacia. Infect Immun $\mathbf{6 5}$, 4281-4287.

Hutchinson, M. L., Poxton, I. R. \& Govan, J. R. (1998). Burkholderia cepacia produces a hemolysin that is capable of inducing apoptosis and degranulation of mammalian phagocytes. Infect Immun 66, 2033-2039.

Isles, A., Maclusky, I., Corey, M., Gold, R., Prober, C., Fleming, P. \& Levison, H. (1984). Pseudomonas cepacia infection in cystic fibrosis: an emerging problem. J Pediatr 104, 206-210.

Jett, B. D., Hatter, K. L., Huycke, M. M. \& Gilmore, M. S. (1997). Simplified agar plate method for quantifying viable bacteria. Biotechniques 23, 648-650.

Jones, A. L., Beveridge, T. J. \& Woods, D. E. (1996). Intracellular survival of Burkholderia pseudomallei. Infect Immun 64, 782-790.

Kirikae, T., Kirikae, F., Saito, S., Tominaga, K., Tamura, H., Uemura, Y., Yokochi, T. \& Nakano, M. (1998). Biological 
characterization of endotoxins released from antibiotic- treated Pseudomonas aeruginosa and Escherichia coli. Antimicrob Agents Chemother 42, 1015-1021.

Lasfargues, A., Tahri-Jouti, M. A., Pedron, T., Girard, R. \& Chaby, R. (1989). Effects of lipopolysaccharide on macrophages analyzed with anti-lipid A monoclonal antibodies and polymyxin B. Eur J Immunol 19, 2219-2225.

van de Loosdrecht, A. A., Nennie, E., Ossenkoppele, G. J., Beelen, R. H. \& Langenhuijsen, M. M. (1991). Cell mediated cytotoxicity against U937 cells by human monocytes and macrophages in a modified colorimetric MTT assay: a methodological study. $J$ Immunol Methods 141, 15-22.

Lowenstein, C. J., Dinerman, J. L. \& Snyder, S. H. (1994). Nitric oxide: a physiologic messenger. Ann Intern Med 120, 227-237.

Marolda, C. L., Hauröder, B., John, M. A., Michel, R. \& Valvano, M. A. (1999). Intracellular survival and saprophytic growth of isolates from the Burkholderia cepacia complex in free-living amoebae. Microbiology 145, 1509-1517.

Martin, C. A. \& Dorf, M. E. (1990). Interleukin-6 production by murine macrophage cell lines P388D1 and J774A.1: stimulation requirements and kinetics. Cell Immunol 128, 555-568.

Mehta, P. K., King, C. H., White, E. H., Mutagh, J. J. \& Quinn, F. D. (1996). Comparison of in vitro models for the study of Mycobacterium tuberculosis invasion and intracellular replication. Infect Immun 64, 2673-2679.

Miliotis, M. D. (1991). Acridine orange stain for determining intracellular enteropathogens in HeLa cells. J Clin Microbiol 29, 830-831.

Nibbering, P. H. \& Van Furth, R. (1988). Quantitative immunocytochemical characterization of four murine macrophage-like cell lines. Immunobiology 176, 432-439.

Oelschlaeger, T. A. \& Tall, B. D. (1997). Invasion of cultured human epithelial cells by Klebsiella pneumoniae isolated from the urinary tract. Infect Immun 65, 2950-2958.

Perotto, S. \& Bonfante, P. (1997). Bacterial associations with mycorrhizal fungi: close and distant friends in the rhizosphere. Trends Microbiol 5, 496-501.

Rost, F. W. D. (1995). Fluorescence Microscopy. Cambridge: Cambridge University Press.

Salzman, G. C., Singham, S. B., Johnston, R. G. \& Bohren, C. F. (1990). Light scattering and cytometry. In Flow Cytometry and Sorting, pp. 81-107. Edited by M. R. Melamed, T. Lindmo \& M. L. Mendelsohn. New York: Wiley-Liss.

di Sant'Agnese, P. A. \& Davis, P. B. (1976). Research in cystic fibrosis. N Engl J Med 295, 597-602.

Shaw, D., Poxton, I. R. \& Govan, J. R. (1995). Biological activity of Burkholderia (Pseudomonas) cepacia lipopolysaccharide. FEMS Immunol Med Microbiol 11, 99-106.
Smith, J. J., Travis, S. M., Greenberg, E. P. \& Welsh, M. J. (1996). Cystic fibrosis airway epithelia fail to kill bacteria because of abnormal airway surface fluid. Cell 85, 229-236.

Smith, A. W., Green, J., Eden, C. E. \& Watson, M. L. (1999). Nitric oxide-induced potentiation of the killing of Burkholderia cepacia by reactive oxygen species: implications for cystic fibrosis. J Med Microbiol 48, 419-423.

Speert, D. P., Bond, M., Woodman, R. C. \& Curnutte, J. T. (1994). Infection with Pseudomonas cepacia in chronic granulomatosis disease: role of non-oxidative killing by neutrophils in host defense. J Infect Dis 170, 1524-1531.

Stuehr, D. J. \& Marletta, M. (1985). Mammalian nitrate biosynthesis: mouse macrophages produce nitrite and nitrate in response to Escherichia coli lipopolysaccharide. Proc Natl Acad Sci USA 82, 7738-7742.

Stuehr, D. J. \& Marletta, M. (1987). Induction of nitrite/nitrate synthesis in murine macrophages by BCG infection, lymphokines or interferon- $\gamma$. J Immunol 139, 518-525.

Summersgill, J. T., Powell, L. A., Buster, B. L., Miller, R. D. \& Ramirez, J. A. (1992). Killing of Legionella pneumophila by nitric oxide in gamma-interferon-activated macrophages. J Leukoc Biol 52, 625-629.

Vandamme, P., Holmes, B., Vancanneyt, M. \& 8 other authors (1997). Occurrence of multiple genomovars of Burkholderia cepacia in cystic fibrosis patients and proposal of Burkholderia multivorans sp. nov. Int J Syst Bacteriol 47, 1188-1200.

Venkataprasad, N., Shiratsuchi, H., Johnson, J. L. \& Ellner, J. J. (1996). Induction of prostaglandin E2 by human monocytes infected with Mycobacterium avium complex: modulation of cytokine expression. J Infect Dis 174, 806-811.

Vosbeck, K., Tobias, P., Mueller, H., Allen, R. A., Arfors, K. E., Ulevitch, R. J. \& Sklar, L. A. (1990). Priming of polymorphonuclear granulocytes by lipopolysaccharides and its complexes with lipopolysaccharide binding protein and high density lipoprotein. J Leukoc Biol 47, 97-104.

Wewers, M. D. (1997). Cytokines and macrophages. In Cytokines in Health and Disease, pp. 339-355. Edited by D. G. Remick \& J. S. Friedland. New York: Marcel Dekker.

Yao, Z., Liu, H. \& Valvano, M. A. (1992). Acetylation of O-specific lipopolysaccharides from Shigella flexneri $3 \mathrm{a}$ and $2 \mathrm{a}$ occurs in Escherichia coli K-12 carrying cloned S. flexneri $3 \mathrm{a}$ and $2 \mathrm{a} r f b$ genes. J Bacteriol 174, 7500-7508.

Zughaier, S. M., Ryley, H. C. \& Jackson, S. K. (1999). Lipopolysaccharide (LPS) from Burkholderia cepacia is more active than LPS from Pseudomonas aeruginosa and Stenotrophomonas maltophilia in stimulating tumour necrosis factor alpha from human monocytes. Infect Immun 67, 1505-1507.

Received 14 June 1999; revised 17 August 1999; accepted 24 August 1999. 